\title{
Análisis de los impactos de la Conservación de Documentos en la legislación cubana.
}

\section{Analysis of the blows of the Conservation of \\ Documents in Cuban legislation.}

\author{
Yorlis Delgado López \\ yorlis.delgado82@gmail.com \\ Academia de Ciencias de Cuba/Universidad de La Habana
}

\section{Resumen}

La conservación documental es y ha sido el tema más regulado en Cuba desde 1559, año en que se emiten las Ordenanzas del Rey Don Felipe II, donde se indicaba a los miembros de las colonias tratar bien los libros y demás documentos. Esta tradición se mantiene hasta nuestros días con las regulaciones vigentes. Debido a esta condicionante se presenta este trabajo cuyo fin es Valorar la regulación jurídica de la conservación documental en Cuba desde la legislación de archivos. Se hace el análisis comparado con otras naciones del área iberoamericana y se toman los principales aspectos relacionados con el tema. Abarca un estudio de la evolución de esta temática en la legislación archivística cubana, enfatizando en el tratamiento legal que es objeto hoy.

Palabras clave

Conservación Documental, documentos, disposiciones, Legislación Archivística, Cuba.

\section{Abstract}

Documentary conservation is and has been the most regulated issue in Cuba since 1559, the year in which the Ordinances of King Don Felipe II were issued, where members of the colonies were instructed to treat books and other documents well. This tradition is maintained until today with current regulations. Due to this 
condition, this work is presented whose purpose is to assess the legal regulation of document conservation in Cuba from the archive's legislation. The analysis is made compared to other nations in the Latin American area and the main aspects related to the subject are taken. It covers a study of the evolution of this theme in Cuban archival legislation, emphasizing the legal treatment that is the subject today.

\section{Keywords}

Documentary Conservation, documents, provisions, Archival Legislation, Cuba.

Recibido: 20/11/2019

Aceptado: 14/12/2019

DOI: https://dx.doi.org/10.5557/IIMEI10-N19-035054

Descripción propuesta: Delgado-López, Yorlis. Análisis de los impactos de la Conservación de Documentos en la legislación cubana. Métodos de Información, 10(19), $35-54$

\section{Media documentation and biometrics}

Los documentos son evidencia del actuar de las personas naturales y jurídicas. Su gestión y relaciones, en sentido general, tienen un reflejo material en los registros que estos generan durante su vida. Esta condicionante ha movido, desde tiempos remotos, a los legisladores y los ha ocupado en preservar la papelería que generan las instituciones y aquellos sujetos, que, desde una actitud artística, científica, política, intelectual, etc., han tenido una influencia en la sociedad.

En Cuba siempre hubo la intención legislativa de conservar los documentos, a pesar de no existir todas las condiciones objetivas para hacerlo. La conservación documental es y ha sido el tema más regulado desde 1559, año en que se emiten las Ordenanzas del Rey Don Felipe II, donde se indicaba a los miembros de las colonias tratar bien los libros y demás documentos. Esta tradición se mantiene hasta nuestros días con las disposiciones vigentes.

El objetivo es entonces, valorar la regulación jurídica de la conservación documental en Cuba desde la legislación de archivos. Para lograr este fin, se hace un análisis 
comparado con tres naciones de área iberoamericana de los principales aspectos relacionados con el tema y abarca un estudio de la evolución de esta temática en la legislación archivística cubana, enfatizando en el tratamiento legal que es objeto hoy.

Para encausar este estudio, más que analizar una definición propia de Conservación Documental, sería oportuno, valorar las implicaciones que ha tenido para el Derecho esta categoría científica. Para contextualizar el término se asumen los siguientes indicadores para encausar el siguiente análisis:

- Regulación desde definiciones legales.

- Deber de conservar el documento.

- Establecimiento de procedimientos para destruir los registros.

- Regulación de trasferencias documentales en términos preestablecidos.

- Normas para la exportación e importación de bienes documentales

\section{Una mirada internacional a la Conservación Documental desde la legislación de archivos}

La conservación documental ha sido una constante preocupación a nivel internacional e indiscutiblemente ha tenido una repercusión en las normas jurídicas, sobre todo en las referentes a archivos. Una pequeña al azar muestra de tres países (Costa Rica, República Dominicana y México), muy cercanos por la distancia geográfica a Cuba, con data legislativa resiente y todos del área centroamericana, permitirá fundamentar esta tesis.

En Costa Rica la actividad archivística se norma por la Ley No. 7202 "Del Sistema Nacional de Archivos" de 24 de octubre de 1990. Esta norma desde su artículo No. 4 establece que los documentos considerados de "... valor científico-cultural deben ser custodiados en los diversos archivos administrativos públicos del país". (Costa Rica 1990) y la obligación de transferirlos a la Dirección del Archivo Nacional. Reconoce la función de conservar de sus archivos desde el Archivo Nacional, los centrales y los de gestión. 
Es interesante como esta disposición regula la obligatoriedad de los archivos centrales de trasferir en un plazo de hasta veinte años sus documentos hasta el punto de disponer la posibilidad del Archivo Nacional de acceder a la vía judicial en materia civil en caso de incumplimientos de estas normativas. Además, la predicción de conservar la documentación de las organizaciones que desaparezcan por una razón legal.

Artículo 50 -Si una entidad desapareciera, entregará sus documentos y los respectivos instrumentos descriptivos directamente a la Dirección General del Archivo Nacional. (Costa Rica 1990)

En el interés de que se conserven los documentos resultantes de la gestión de los Presidentes de la Republica y los principales funcionarios del país, la Ley dispone la obligación de que estos entreguen su papelería.

Artículo 53 -La Presidencia de la República y los ministros de Estado, al terminar sus funciones, entregarán a la Dirección General del Archivo Nacional los documentos de sus despachos que hayan concluido su trámite de gestión. Igualmente, entregarán las actas del Consejo de Gobierno. Dicha transferencia deberá realizarse a más tardar durante la semana anterior al traspaso de poderes. (Costa Rica 1990)

Faculta a la Comisión Nacional de Selección y Eliminación de Documentos, órgano colegiado, para que valore los documentos y pueda dilucidar que retener o preservar de los archivos de la administración pública. (Costa Rica 1900)

En la República Dominicana se regula la actividad documental por la Ley No. 481-08 "General de Archivos de la República Dominicana", de 11 de diciembre de 2008. Esta disposición, desde el concepto básico de un archivo se reconoce la función de conservar de los archivos, con énfasis luego, el situar las finalidades en cada una de los archivos integrantes del Sistema Nacional. Por ejemplo:

- Archivo General es el encargado de "...preservar el patrimonio documental producto de la gestión del Estado y de la acción privada" (República Dominicana 2008) y "Seleccionar, organizar, conservar y divulgar el acervo documental que integra el SNA" (República Dominicana 2008). 
- Archivos Públicos. "Los titulares de las instituciones públicas son los responsables por las condiciones de conservación y organización en que se encuentran sus respectivos archivos" (República Dominicana 2008)

Específicamente regula sobre la conservación de Documentos regula que:

"Los archivos institucionales del sector público deben implementar un sistema integrado de conservación en cada una de las fases del ciclo vital de los documentos, el cual debe ser diseñado con la asesoría y el concurso del AGN”. (República Dominicana 2008)

Faculta a la Comisión de Evaluación y Acceso de Fondos Documentales del AGN para decidir lo relativo a que retener o preservar de los archivos de la administración pública. (República Dominicana 2008).

En México la Ley General de Archivos de los Estados Mexicanos, normativa sancionada el 15 de junio de 2018, pondera la conservación documental al citarla ente los objetivos de esta disposición: Promover la organización, conservación, difusión y divulgación del patrimonio documental de la Nación. (Estados Mexicanos 2018)

Más adelante, en las normas relativas a las definiciones legales anuncia un grupo de conceptos para aquella conformación es imprescindible la preservación y dedica todo un acápite a definirla.

Conservación de archivos: Al conjunto de procedimientos y medidas destinados a asegurar la prevención de alteraciones físicas de los documentos en papel y la preservación de los documentos digitales a largo plazo... (Estados Mexicanos 2018)

Establece la obligación general de todos los sujetos de la ley de garantizar la integridad de sus fondos al regular: Cada sujeto obligado es responsable de organizary conservar sus archivos. (Estados Mexicanos 2018)

Dedica todo un capítulo a establecer las bases procedimentales para la entrega de la documentación por los servidores públicos propia de su gestión. Mantiene la misma forma de preceptuar las funciones de conservar a cada uno de los archivos integrantes del Sistema nacional. Muy novedoso resulta el tratamiento legal que da los documentos en soporte electrónicos estableciendo 
para ellos la obligación de conservar de mera permanente a los sujetos de la ley. (Estados Mexicanos 2018)

Da a los grupos interdisciplinarios, comisiones encargadas de valorar, la función de proponer los documentos a conservar de forma permanente.

Dedica un capítulo al área de conocimiento objeto de esta ponencia, estableciendo que al menos, los sujetos, aprueben determinados documentos que garanticen la preservación. Establece normas específicas sobre los documentos considerados Patrimonio Documental de la Nación y regula la capacitación de los sujetos en esta materia (Estados Mexicanos 2018).

Existe coincidencia en la muestra objeto de estudio, más allá de determinadas particularidades, en la ponderación de estos procederes desde las definiciones legales, en la regulación del deber de preservar la documentación generada por la Administración Pública y las regulaciones inherentes a la destrucción de los registros y determinar valores, a través de órganos colegiados. Llama la atención la voluntad desde el derecho, de preservar la papelería generada por las altas esferas del Estado y el Gobierno como muestra de la trasparencia administrativa alcanzada en los países sujetos de la muestra.

Evidentemente la Conservación Documental es uno de los temas archivísticos más aludidos en las disposiciones de archivos de Iberoamérica y en la historia legislativa de estos países, demostrando el interés legislativo de los gobiernos por estas dinámicas sociales.

\section{Una mirada a los antecedentes desde la legislación de archivos en Cuba.}

- En la etapa colonia en Cuba, el poder legislativo de la metrópolis, estuvo muy preocupado por conservar los documentos que servían para demostrar la actuación de las autoridades y personas naturales en la isla. Esta fue indudablemente, durante mucho tiempo, la finalidad principal, de estas organizaciones archivísticas, muy atemperado a las condiciones económicas y políticas de la época.

Tanto es así, que la primera norma que emitió España, las Ordenanzas del Rey Don Felipe II/1559, ordenó a los miembros de las colonias a tratar bien los 
libros y demás papeles (Llaverías 1949). Es presumible que la emisión de esta disposición estuvo motivada por el deterioro y las perdidas documentales que sufrían estos territorios y ello fue objeto de ocupación de la metrópolis.

Ya en 1602, las Ordenanzas del Rey Don Felipe III recomendó el cuidado de los libros de relaciones y los demás de la Real Hacienda y ordenó el buen resguardo de los mismos. Es significativo señalar que esta regulación estableció que los libros fueran renovados y se pusiesen en buena forma, evitando así su deterioro. Se emitió así la primera normativa con indicaciones precisas para la conservación curativa de los documentos (Llaverías 1949).

La Real Orden No. 531/1840 contenía en su texto el primer Reglamento de Archivos de la Real Hacienda de la Isla de Cuba y su regulación estuvo motivada por la necesidad de conservar los papeles antiguos generados por la Real Hacienda y entidades auxiliares (Llaverías 1949). Este documento, muy poco estudiado, contenía la obligación de trasferir al nuevo archivo determinados documentos, según la data de su producción, para su conservación.

ARTÍCULO 2:1 Desde luego se remitirán a él para su custodia, organización y conservación todos los expedientes de aquella clase hasta el año 1830 esclusive en la provincia de la Habana, y hasta 1820 esclusive de Cuba y Puerto Príncipe. (Llaverías 1949).

Resulta muy interesante, como desde época tan temprana España ordena reglas básicas para la conservación documental. En este sentido estableció como y cuando se debería ejecutar la limpieza del archivo, el uso de luz y la prohibición de fumar en cualquiera de los interiores de la organización.

ARTÍCULO 15: Los estantes se sacudirán diariamente, con prolijidad y cada mes todos los legajos observando con atención si en alguno se introduce la polilla, para separarle y da parte a fin de que la Superioridad determine lo que debe hacerse.

ARTÍCULO 16: El archivero y demás empleados del archivo general son responsables en la parte que a cada uno concierne de la custodia a la conservación de los documentos, puestos a su cuidado. (Llaverías 1949).

\footnotetext{
${ }^{1} \mathrm{El}$ autor respeta la ortografía de la época.
} 
ARTíCULO 22: No se usará nunca en el archivo luz artificial, ni se fumará dentro de las salas, cuidando de cerrar bien las ventanas al salir a fin de precaver un incendio. (Llaverías 1949).

El Gobierno Militar en 1900, mediante la Orden No. 40 dispuso la obligatoriedad de conservar los documentos que hasta esa fecha se encontraban en depósito en el Archivo General (Llaverías 1949). En ese mismo año, sustentado en la situación social existente, se emite la Orden No. 74 que autorizó a los encargados de oficinas públicas y archivos para tener en estos locales las armas necesarias para la protección de los fondos y la conservación de sus documentos (Llaverías 1949).

En 1913, el Decreto No. 1233, estableció de manera obligatoria la devolución de los documentos extraídos del Archivo Nacional, en un plazo de quince días, respectivamente (Cuba 1913).

La Ley No. 6/1942 estableció que cualquier persona natural o jurídica que fuese poseedor de un documento histórico, estaba en la obligación de conservarlo. Prohibió la destrucción de los documentos históricos, considerando esta actividad como delictiva y estableció el procedimiento judicial a emplear ante una denuncia de incumplimiento de esta Ley. Dio el derecho de tanteo al Archivo Nacional en lo concernirte a cambios de dominio de los registros. Introdujo la provisión de extracción del país de los documentos (Cuba 1942).

Dos años más tarde, por el Decreto No. 2960, que aprobó el Reglamento General Interior del Archivo Nacional de la República de Cuba, que estableció el régimen de esta entidad dejando bien claro que entre sus finalidades estaba conservar la documentación, teniendo en cuenta las más modernas técnicas y procedimientos de la época (Cuba 1942).

La Ley No. 714/1960 reguló el funcionamiento del Archivo Nacional y mantuvo entre las finalidades la de conservar y custodiar la documentación que la propia ley establece de utilidad pública (Cuba 1960). Es bien interesante la manera en que la ley estableció el deber de cada persona poseedora de documentos históricos, de conservarlo, de no transferirlo o venderlo salvo que lo hiciera con el Archivo Nacional. 
ARTÍCULO 6. Toda persona natural o jurídica que dentro del territorio nacional posea documentos de la índole de los que se especifican en el Artículo 4 de esta Ley, podrá continuar con la tenencia de los mismos sin que ello constituya infracción alguna, siempre y cuando los custodie dentro de condiciones que garanticen su absoluta conservación o integridad, pero en ningún caso podrá destruirlos, alterarlos, sustraerlos al patrimonio nacional, venderlos, gravarlos o hacerlos objeto de transacción a favor de persona o entidad que no sea precisamente el Archivo Nacional de Cuba. (Cuba 1960).

Esta disposición facultó, además, al Archivo Nacional, como conservador de determinados documentos generados por el Estado y el Gobierno de la época.

ARTÍCULO 19. El Archivo Nacional es el depósito de todos los originales de las Constituciones, Estatutos, Leyes Constitucionales, Leyes Fundamentales, Leyes, Acuerdos-Leyes, Decretos-Leyes, Leyes-Decretos y Órdenes Militares de carácter legislativo; así como de los Decretos Presidenciales, Reglamentos, Proclamas y demás resoluciones de carácter general emanados del Poder Ejecutivo del Estado. A estos efectos se declara al Archivo Nacional como depositario de la colección de la Gaceta Oficial de la República, siendo su Director el único funcionario autorizado para expedir certificaciones de cualquier documento público inserto en dicha Gaceta. (Cuba 1960).

ARTÍCULO 21. El Archivo Nacional del Ejército Libertador que se encuentra depositado en el Estado Mayor del Ejército de la República y que es complementario de los documentos de la antigua Inspección del Ejército, será entregado al Archivo Nacional.

ARTíCULO 22. Los Protocolos, libros y demás documentos que forman parte de los archivos notariales permanecerán en poder de los respectivos Notarios o de sus sustitutos legales, por un término de treinta años, conforme a lo dispuesto en el Artículo 110 del Código Notarial. Pasado ese tiempo se entregarán al Archivo General de Protocolos donde se conservarán por un período igual y transcurrido este último plazo irán a engrosar los fondos documentales del Archivo Nacional debiéndose habilitar una o más Salas para conservarlos y protegerlos adecuadamente. (Cuba 1960).

En sus últimos artículos esta ley prohibió en absoluto la extracción de toda clase de piezas documentales del Archivo Nacional y facultó al Director del Archivo como la única autoridad para autorizar la depuración documental en todas las instituciones del país (Cuba 1960). Es significativo recordar que esta disposición de aprobó a casi un año del triunfo de los procesos revolucionarios en Cuba y era preciso impedir cualquier intento de robo, sustracción o deterioro del Patrimonio Documental.

En el Decreto-Ley No. 221/2001 "De los Archivos de la República de Cuba" fue el termino más repetido, ubicándolo en la definición legal de archivo, en las categorías archivo histórico, central y de gestión. De igual manera se empleó al 
definir las funciones del Sistema Nacional y las obligaciones de sus archivos. Similar observación hizo al definir las funciones del Archivo Nacional, los históricos provinciales y municipales, los ramales, los centrales y de gestión (Cuba 2001).

Esta disposición estableció, por primera vez, una disposición general de protección de la conservación a los documentos independientemente de que fueran considerados históricos o no.

Los documentos depositados en archivos, en otros lugares destinados a su conservación oficial o confiados a la custodia de un funcionario no podrán ser sustraídos, alterados, ocultados, destruidos ni deteriorados. (Cuba 2001).

Por primera vez, se estableció un sistema de órganos colegiados (Comisiones de Control y Peritaje) que se encargarían de proponer desde la base generativa de los documentos, que se conservaría y que se destruirá en Cuba (Cuba 2001).

Además, se mantuvo la prohibición de exportar a otros países documentos histórico cubanos, salvo autorización correspondiente. Este salvoconducto, con rango ministerial, debía contener el tiempo de permanencia del registro fuera del país como mecanismo para recuperar, en caso de pérdida u olvido (Cuba 2001).

El Reglamento de este Decreto Ley, aprobado por la Resolución No. 73 del Ministerio de Ciencia, Tecnología y Medio Ambiente (CITMA), fue el primero que introdujo en Cuba un capítulo especial dedicado a la Conservación Documental. Esta norma, específica de esta materia, implementó un grupo de medidas estructuradas y sistémicas que garantizan la preservación de los documentos generados y los que se producirían a partir del momento de promulgación de esta reglamentación. (Delgado 2015).

ARTÍCULO 98. Los archivos deben elaborar e implementar una política de conservación preventiva acorde a las características propias de la entidad y siguiendo las normas técnicas vigentes al efecto, con el propósito de garantizar la integridad física y funcional de toda la documentación desde su creación hasta su puesta en servicio. (Delgado 2011). 
Además, prestableció las normas muy generales de gestión de riegos, conservación preventiva y restauración documental.

El Grafico $\mathrm{N}^{\circ} .1$ muestra un resumen de las normativas inherentes a la conservación documental en Cuba. Ello evidencia la preocupación y ocupación que, en el tema en cuestión, tuvieron los Gobiernos. Es importante tener en cuenta que el tema más legislado ha sido el acceso a los registros públicos y como acceder si no se garantiza que existan en buen estado los documentos.

Gráfico 1. Relación entre disposiciones aprobadas en Cuba relacionadas con archivos y con conservación documental.

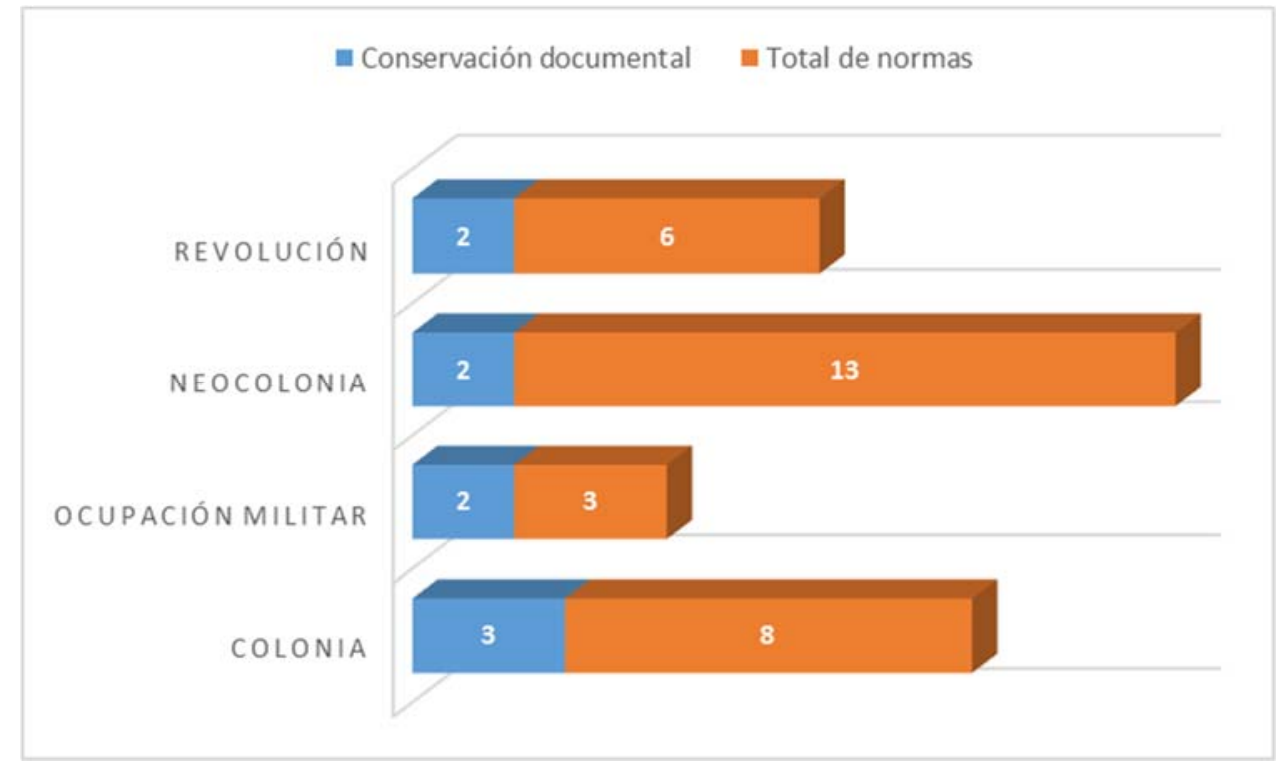

Fuente: Elaboración propia.

\section{Una mirada a las disposiciones vigentes desde la legislación de archivos en Cuba.}

En el Decreto-Ley No. 265/2009 "Del Sistema Nacional de Archivo de la República de Cuba" es la normativa vigente en Cuba en esta materia. Esta regulación mantiene el término Conservar como más repetido. Da un valor muy significativo a la conservación como elemento constitutivo al definir como documento de archivo (Cuba 2009).

Documento de Archivo: Aquel en el que se refleja el testimonio material de un hecho o acto realizado por persona natural o jurídica en el ejercicio de sus funciones y que por su valor 
administrativo, legal, fiscal, científico, económico, histórico, político o cultural, debe ser objeto de conservación. (Cuba 2009).

Además, ubica esta finalidad entre la más transcendentales de un archivo.

Archivo: Institución o una parte estructural de ella, que realiza la recepción, organización y conservación de los documentos para su utilización; (Cuba 2009).

Es muy interesante como desde la parte general de la norma se pone claro la responsabilidad de las entidades del Estado y el Gobierno cubano sobre la integridad de los documentos y de las condiciones materiales para garantizar la conservación.

ARTICULO 6.-Las instituciones y organizaciones donde están ubicados los archivos, tienen la obligación de velar por la integridad de los fondos documentales bajo su custodia y la seguridad de éstos, por la fidelidad de los testimonios que se ofrezcan, así como de garantizar que no se divulgue información que pueda afectar los derechos de las personas jurídicas o naturales. Además, responden por las condiciones materiales que posibilitan la organización, preservación de los archivos a su cargo y por la prestación oportuna y eficiente de los servicios a investigadores, organizaciones y población en general. (Cuba 2009).

Seguidamente la introduce como una causal para limitar el acceso a los documentos. Esta condición es la más objetiva y práctica de las limitantes de acceso y a veces no reconocida por algunas legislaciones del área. El autor la considera, además, necesaria pues en ocasiones es mejor no acceder y preservar un documento antes que se destruya para siempre.

ARTICULO 7.-La dirección de cada archivo, atendiendo al estado de conservación, a la confidencialidad de la información que contienen, y a la protección de los derechos de las personas naturales y jurídicas refrendados legalmente, puede restringir el acceso a determinados documentos. (Cuba 2009).

Igual que se antecesora, mantiene la obligación de conservar de las entidades y sus funcionarios.

ARTICULO 8.-Los documentos depositados en archivos, en otros lugares destinados a su conservación oficial, o confiados a la custodia de un funcionario, no pueden ser sustraídos, alterados, ocultados, destruidos ni deteriorados. (Cuba 2009)

Igual formulación tiene el delito de "Sustracción y Daño de documentos u otros objetos en custodia oficial y violación de sellos oficiales" preceptuado en 
el Código Penal ${ }^{2}$ vigente como forma, además, de afianzar la norma y el deber hacer de los funcionarios hacia la documentación y su conservación.

ARTICULO 168.1.- El que sustraiga, altere u oculte documentos, legajos, papeles u objetos depositados en archivos y otros lugares destinados a su conservación oficial o confiados a la custodia de un funcionario público, o intencionalmente los destruya o deteriore, incurre en sanción de privación de libertad de tres meses a un año o multa de cien a trescientas cuotas.

2. Si el hecho se comete por el funcionario público encargado de la custodia de los documentos u objetos a que se refiere el apartado anterior, o con abuso de su cargo, o por quien, sin ostentar este carácter los tiene a su disposición en cumplimiento de un trámite legal o por cualquier otro motivo legítimo, la sanción es de privación de libertad de uno a tres años o multa de trescientas a mil cuotas. (Cuba 1987)

Uno de los grandes problemas que existe en el país, son los cambios de mandos entre dirigentes y funcionarios, pues en la premura necesaria de los medios básicos y el cumplimiento de las funciones, muchas veces se olvida la papelería resultante de la gestión y su importancia para la organización. A tratar de solucionar esta disyuntiva se va esta norma, poniendo este requerimiento al nivel del plan de entrega del cargo.

ARTICULO 9.-Los dirigentes y funcionarios de instituciones estatales radicadas en el territorio nacional, están obligados a garantizar el traspaso de la documentación resultante de su gestión, como parte del plan de entrega del cargo. (Cuba 2009)

Muy interesante resulta la facultad que confiere esta disposición al Archivo Nacional, los provinciales y municipales para incautar la documentación cuando sus poseedores haya incumplido las especificidades normativas para la conservación y por ello se ponga en peligro el documento. Esta es una de las normas que más urge reglamentar pues su implantación es necesaria y útil al país.

ARTICULO 10.-El Archivo Nacional de la República de Cuba y los archivos históricos provinciales y municipales pueden disponer el traslado de fondos y colecciones a sus instalaciones, cuando se incumplan por sus poseedores los requerimientos establecidos para la conservación y tratamiento de los documentos y que pongan en riesgo su integridad física. El procedimiento para el cumplimiento de la disposición anterior, se establece en el Reglamento de este Decreto-Ley (Cuba 2009).

\footnotetext{
${ }^{2}$ Aprobado por la Ley No. 62/1987
} 
El Decreto- Ley No.265/2009 mantiene, como sus antecesoras y sus similares, en el área la conservación entre las funciones de un archivo y todas las variantes de instituciones con estos fines.

ARTICULO 12.-Entre las funciones fundamentales del Archivo Nacional de la República de Cuba se encuentran:

a) atesorar, organizar, custodiar, conservar y difundir la documentación de valor histórico o permanente de carácter nacional; (Cuba 2009).

ARTICULO 16.-Entre las funciones fundamentales de los archivos históricos provinciales y municipales se encuentran:

b) atesorar, organizar, custodiar, conservar y difundir la documentación de valor histórico o permanente correspondiente a sus territorios; (Cuba 2009).

ARTICULO 20.-Entre las funciones fundamentales de los archivos centrales se encuentran:

c) conservar por el término de hasta veinticinco años la documentación producida por los archivos de gestión que les sean tributarios, que aún mantenga vigencia administrativa, pero cuya consulta ya no es frecuente,

d) transferir sus documentos de valor histórico o permanente, de acuerdo con los plazos de retención que se establezcan, al archivo histórico correspondiente;

a. asumir, dentro de su esfera de acción, la documentación de archivos de una entidad que se extinga; (Cuba 2009)

ARTICULO 21.-Los archivos de gestión u oficina son archivos vigentes, activos, que guardan con carácter temporal los documentos que se encuentran al servicio de la institución a la cual pertenecen. Conservan los documentos sometidos a continua utilización y consulta por las propias oficinas, transfiriéndolos, al término de los plazos establecidos, al archivo central correspondiente o en su caso a los archivos históricos provinciales o municipales. (Cuba 2009)

ARTICULO 24.-Los archivos universitarios conservan los documentos de cualquier fecha, formato o soporte material, producidos o reunidos en el desarrollo de las funciones y actividades de los diferentes centros de educación superior que brindan un servicio especializado en la gestión, conservación y difusión de los mismos, con finalidades administrativas, docentes e investigativas. (Cuba 2009).

ARTICULO 28.-Los archivos especiales conservan los documentos cuyo soporte no es papel y aquellos en papel asociados a éstos, y están obligados a adoptar las medidas correspondientes para la conservación de los mismos. ((Cuba 2009).

Además, reguló que los documentos técnicos de una determinada especialidad que son de utilidad y continua utilización por esa institución, siendo difícil predecir la perdida de sus valores administrativos, no sean trasferido de la oficina productora. Precisó la responsabilidad del sujeto generador de tales registros de garantizar los recursos para conservar y prestar servicios. 
ARTICULO 23.-Los documentos técnicos propios de una determinada especialidad, de frecuente consulta, no se transfieren a los archivos históricos, quedando obligado el productor de la documentación a adoptar las medidas correspondientes para la conservación permanente de la misma, con vistas a la prestación de los servicios a usuarios. (Cuba 2009).

Estableció que los poseedores de documentos históricos declarados de utilidad pública están en la obligación de conservarlos y dar cuenta al registro del Fondo Estatal de Archivo de cualquier transacción de dominio (Cuba 2009).

Además, prohibió su extracción del país salvo autorización ministerial siguiendo igual redacción que su antecesora.

De igual manera, estableció un sistema de órganos colegiados (Comisiones de Valoración Documental) que se encargarían de proponer que se conservaría y que pasaría por los procesos de depuración documental (Cuba 2009).

Por último, el Decreto- Ley trata de resolver otro de los males causantes de perdidas documentales en la isla. Una errónea interpretación de las normas de Protección de la Información Oficial vigente ha condicionado que muchos de los documentos calificados sean destruidos y no sean sometidos a un proceso de descalificación como la norma establece. Ante lo cual esta norma regula:

ARTICULO 53.-Las personas jurídicas que constituyen fuente de completamiento y poseen documentos con Información Oficial, Clasificada o Limitada, están en la obligación de conservarla hasta que una vez perdida tal condición, según lo previsto en la legislación para la Protección de la Información Oficial vigente, sea transferida al archivo correspondiente, donde se definen las restricciones de acceso, en los casos necesarios. (Cuba 2009).

Es digno resaltar, que la única norma complementaria que tienes esta disposición es la Resolución No. 41 del Ministerio de Ciencia, Tecnología y Medio Ambiente de 26 de mayo de 2009 que aprueba y pone en vigor los “Lineamientos para la Conservación de las Fuentes Documentales". En tal sentido es importante resaltar que este es el primer instrumento jurídico dedicado a normalizar los procesos de conservación de los documentos en Cuba y es, a criterio del autor, es en sí misma una gran proeza, pues es una de las pocas que se conocen en América Latina, para no ser absoluto, que eleva esta temática al rango de disposición ministerial (Cuba 2009). 
Esta norma repercute directamente sobre la conservación de los documentos el país en cualquiera de sus soportes. Permite un mayor control del tema pues preestablece los parámetros de conservación que deben tener los depósitos de archivos en cualquier Organismo o entidad nacional. Asimismo, asigna determinados requisitos a los que se encarguen de su conservación en las entidades.

\section{La obligación de conservar por otras disposiciones.}

Aunque la regulación de archivos establece normas generales de conservación para todos los documentos generados por instituciones y entidades cubanas, el legislador ha establecido reglas para tipos documentales específicos que estas actividades generan. Se observa la fortaleza que, en todos los casos, se hace en el marco de los parámetros archivísticos establecidos. A continuación, se presentan algunos ejemplos:

\section{Documentos integrantes del Patrimonio Cultural de la Nación: E1} "Reglamento para la ejecución de la Ley de Protección al Patrimonio" aprobado por Decreto No. 118 de 23 de septiembre de 1983, protege los bienes integrantes del Patrimonio Cultural de la Nación. Considera, entre esta categoría a un grupo de documentos importantes dentro de tales bienes. Es importante reconocer que en la lista tacita de bienes la mayoría son registros documentales.

a) Los documentos y demás bienes relacionados con la historia, con inclusión de las de la ciencia y la técnica, así como con la vida de los forjadores de la nacionalidad y la independencia, dirigentes y personalidades sobresalientes, y con los acontecimientos de importancia nacional e internacional;

e) los objetos y documentos etnológicos o folklóricos,

f) los manuscritos raros, incunables y otros libros, documentos y publicaciones de interés especial,

g) los archivos, incluidos los fotográficos, fonográficos y cinematográficos;

h) los mapas y otros materiales cartográficos, partituras originales o impresas, ediciones de interés especial y grabaciones sonoras;

i) los objetos de interés numismático y filatélico, incluidos los sellos fiscales y otros análogos, sueltos o en colecciones; (Cuba 1983)

Más adelante regula que todo propietario, poseedor, usuario o tenedor por cualquier título de un bien declarado parte del Patrimonio Cultural de la 
Nación, inscripto o no en el Registro Nacional de Bienes Culturales de la República de Cuba, estará obligado a garantizar su conservación y absoluta integridad. Se considera adecuado por el valor y necesidad de preservación de tal papelería.

Documentos notariales: Estos registros son insoslayablemente importantes. No solo muestran la historia jurídica, sino el amplio abanico de las relaciones históricos, sociales. En relación con ello la Ley No. 50 "Ley De Las Notarías Estatales" de 28 de diciembre de 1984 previo que en cada provincia del país radicaría un archivo de protocolos notariales a cargo de un Notario. En estos archivos se encuentran depositados los protocolos con más de veinte y hasta cuarenta años de antigüedad, transcurrido este término será transferidos al Archivo Nacional de Cuba.

Expediente laboral: Estos registros tienen gran importancia para las personas naturales, su conservación es vital a la hora de enfrentar determinados procesos jurídicos. El Reglamento del Código de Trabajo aprobado por el Decreto No. 326 de 12 días del mes de junio de 2014, estableció que en caso del trabajador que abandona su entidad sin que se conozca su paradero, fallece o se le impone una sanción de privación de libertad, el expediente laboral se conserva durante cinco años. Si en ese período no se solicita por el trabajador o sus familiares, se archivan los documentos que acrediten tiempo de trabajo y salarios devengados, dejando constancia en acta firmada por un representante del jefe de la entidad y de la organización sindical, y el resto se incinera.

Esta regulación llega a establecer hasta los registros imprescindibles para reconstruir la historia laboral del sujeto.

Documentos del expediente de control y de Auditorias: Por el "Reglamento de la Ley No. 107/09 de la Contraloría General de la República de Cuba" aprobado el 30 de septiembre de 2010 se protege los documentos contenidos en el expediente de las acciones de control a las entidades gubernamentales. Se establece que los mismos serán son mostrados a las autoridades facultadas que, en el ejercicio de sus funciones, lo interesen y se conservan por un período de cinco años salvo que, por su importancia, el 
máximo dirigente de la entidad auditada y la persona natural responsabilizados de su custodia según corresponda, determinen un tiempo superior, en correspondencia con la legislación vigente en materia de archivo.

Igual redacción se logró para los expedientes de auditoria siempre regulando el deber hacer inherente a la conservación de estos registros.

Estos ejemplos demuestran que la legislación específica regula la obligatoriedad de preservar aquellos tipos documentales que el Estado considera imprescindibles para su gestión y la historia patria.

\section{Conclusiones}

- Cuba cuenta con una importante y hermosa tradición legislativa en materia de protección de los documentos y el funcionamiento de sus archivos.

- La Conservación Documental es uno de los temas archivísticos más aludidos en las disposiciones de archivos de Iberoamérica y en la historia legislativa cubana, demostrando el interés legislativo de los gobiernos por estas dinámicas sociales.

- En Cuba siempre hubo la intención legislativa de conservar los documentos, a pesar de no existir todas las condiciones objetivas para hacerlo.

- La legislación cubana ha ido evolucionando de tal manera que se ha logrado la protección jurídica del documento y su conservación, poniendo este ultimo proceso como prioridad dentro del tracto legislativo.

- La normativa vigente en Cuba en materia de archivos protege la conservación como requisito imprescindible para desarrollar los demás procedimientos sobre la documentación.

La legislación general de archivos, vigente en Cuba, regula el deber hacer en materia de Conservación Documental, no obstante, la legislación específica regula la obligatoriedad de preservar aquellos tipos documentales que el Estado considera imprescindibles para su gestión y la historia patria 


\section{Bibliografía}

ABERRCH-FULGERAS, R., 2013. Archivos. Editorial UOC, Barcelona, España.

ARCHIVO GENERAL DE LA NACIÓN, 1997. Hacia un diccionario de la terminología archivistica. GITAA. SAntafe de Bogotá, DC.

COLECTIVO DE AUTORES, 2008. Manual de Procedimientos para el tratamiento documental. Editorial Archivo Nacional de la República de Cuba y Archivo General de la Nación de República Dominicana. Santo Domingo República Dominicana

COSTA RICA, 1990. Ley No. 7202 "Del Sistema Nacional de Archivos de Costa Rica", 1990.

Disponible

en

http://www.archivonacional.go.cr/pdf/ley 7202.doc

CUBA, 1913. Decreto No. 1233. Gaceta Oficial de la República de Cuba No. 150 de 23 de diciembre de 1913.

CUBA, 1942. Ley No. 6. Gaceta Oficial de la República de Cuba No. 280 de 09 de mayo de 1942.

CUBA, 1944. Decreto No. 2960. Gaceta Oficial de la República de Cuba No. XVIII de 19 de septiembre de 1944.

CUBA, 1960. Ley No. 714. Gaceta Oficial de la República de Cuba No. 17 de 26 de enero de 1960.

CUBA, 1982. Ley No. 37 "Ley Electoral" Disponible en http://www.parlamentocubano.cu/index.php/documento/ley-electoral/

CUBA, 1983. Decreto No. 118 "Reglamento para la ejecución de la Ley de Protección al Patrimonio". Disponible en http://www.cnpc.cult.cu/sites/default/files/DECRETO\%20No.\%20118.pd $\underline{f}$

CUBA, 1984. Ley No. 50 "Ley De Las Notarías Estatales". Disponible en http://www.parlamentocubano.cu/index.php/documento/ley-de-lasnotarias-estatales/

CUBA, 1987. Ley No. 62 "Código Penal. Disponible en https://www.gacetaoficial.gob.cu/html/codigo penal.html

CUBA, 2001. Decreto-Ley No. 221 "De los Archivos de la República de Cuba". Gaceta Oficial de la República de Cuba Edición Ordinaría No.57 de 13 de agosto de 2001.

CUBA, 2009. Decreto-Ley No. 265 "Del Sistema Nacional de Archivos de la República de Cuba”. Gaceta Oficial de la República de Cuba. Edición Ordinaria No. 18 de 05 de mayo de 2009. 
CUBA, 2009. Resolución No. 41 del Citma. "Lineamientos para la Conservación de las Fuentes Documentales”. Gaceta Oficial de la República de Cuba, Edición Ordinaria No. 008 de 09 de marzo de 2009.

CUBA, 2014. Decreto No. 326 "Reglamento del Código de Trabajo". Gaceta Oficial No. 29, extraordinaria No. 29 de 17 de junio de 2014.

DELGADO LÓPEZ, Y., 2015. Legislación Archivística. Compendio Normativo. Editorial Pueblo y Educación. La Habana.

ESTADOS MEXICANOS, 2018. Ley General de Archivos de los Estados Mexicanos. http:/ www.dof.gob.mx/nota detalle.php? codigo $=5526593 \&$ fecha $=15 / 06 /$ 2018.

JEAN, LUIS F, 2007. La legislación archivística en América Latina. Disponible en http://www.ts.ucr.ac.cr/ historia/articulos/legis-arch.htm.

LLAVERÍAS MARTÍNEZ, J., 1949. Historia de los Archivos de Cuba, Segunda Edición. Publicaciones del Archivo Nacional de Cuba. XXIV. La Habana, Cuba.

MENDOZA NAVARRO, A., 2002. Legislación Archivística: lo que el archivero debe conocer. Perú Textos Editores, Lima, Perú.

MESA LEÓN, M., 2002. Pasado y presente de la legislación archivística cubana: un estudio a partir de su correspondencia con los principios del Consejo Internacional de Archivos. [Congreso] La Habana, 2002. Disponible en http://www.congresoinfo.cu/UserFiles/File/Info/Info2002/Ponencias/183 pdf.

REPÚBLICA DOMINICANA, 2008. Ley No. 481-08 “General de Archivos de la República Dominicana". Disponible en http://archivosiberoamericanos.org/wp-content/uploads/2013/03/Ley-deArchivos-481 08.pdf 